\title{
Tetraploidy: A New Marker for Breast Cancer?
}

\section{Jaroslava Halper*}

Department of Pathology, College of Veterinary Medicine and Medical Partnership, The University of Georgia, Athens, GA 30602, USA

In this issue Sennerstam and Strömberg are reporting on the occurrence of polyploidization in breast cancer [1]. In particular, they are concerned about tetraploidy as a phenomenon occurring at two points of breast carcinogenesis: as an intermediate state, when it is still reversible (as in precancerous stage), or when the tumor reaches certain size and is on the way to aneuploidy, and genomic instability. So it is important to distinguish between the "benign", precancerous and the more ominous, leading to genomic instability tetraploidy. The authors show that this is feasible using a parameter reflecting genomic instability and proliferative activity (Stemline Scatter Index, or SSI) on a consecutive sample of 519 breast cancer patients collected over a period of 17 years which allowed follow up of patients.

How can this be applied in practice? As it is widely known, evaluation of breast carcinoma for the presence or absence of several markers has become routine and it is an important component of determination how treatment modalities and protocols should be individualized for each particular patient with a specific profile of markers. Besides histologic grade and staging, testing for estrogen receptors and HER2 has become pretty much routine. Mutations in $B R C A 1$ and $B R C A 2$ genes have been known to play important roles in the pathogenesis of breast cancer, and molecular profiling assays looking at a variety of genes, including $B R C A s$ are quickly becoming another useful tool to determine an optimal course of therapy. As far as tetraploidy is concerned according to Jonsdottir et al. it is significantly more frequent in BRCA2-mutated than sporadic breast carcinomas, and it is confined to luminal type of tumors rather than to tumors bearing triple-negative phenotype [2]. The authors hypothesize that BRCA2 mutations facilitate polyploidisation through cytokinesis failure as well as through creation of chromosome bridges [2], however, they do not discuss the presence of "benign" reversible tetraploidy. Tetraploid cells are usually eliminated by immunological means which can be potentially enhanced by suitable chemotherapy [3]. Again, the assumption here is that these cells are on the way to aneuploidy. However, one can speculate

Circulating breast tumor cells could also be a source of tetraploid cells as many of them give rise to metastases [4], so it might be even more essential to apply SSI assessment to this subset of tumor cells.

What is your experience? We woud like to hear about it so please share it with us either in the form of a research report or a clinical study!

\section{References}

1. Sennerstam RB, Strömberg JO. Hyperdiploidy tetraploidization and genomic instability in breast cancer - a case report study. J Carcin Mutagenesis DOI: 10.4172/2157-2518.1000144.

2. Jonsdottir AB, Stefansson OA, Bjornsson J, Jonasson JG, Ogmundsdottir HM et al. (2012) Tetraploidy in BRCA2 breast tumours. Eur J Cancer 48: 305-310.

3. Senovilla L, Vitale I, Martins I, Kepp O, Galluzzi L, et al. (2013) An anticancer therapy-elicited immunosurveillance system that eliminates tetraploid cells. Oncoimmunology 2: e22409.

4. Nadal R, Lorente JA, Rosell R, Serrano MJ (2013) Relevance of molecular characterization of circulating tumor cells in breast cancer in the era of targeted therapies. Expert Rev Mol Diagn 13: 295-307.
*Corresponding author: Jaroslava Halper, Department of Pathology, College of Veterinary Medicine and Medical Partnership, The University of Georgia, Athens, GA 30602, USA, E-mail: jhalper@uga.edu

Received June 19, 2013; Accepted June 27, 2013; Published July 10, 2013

Citation: Halper J (2013) Tetraploidy: a New Marker for Breast Cancer? J Carcinogene Mutagene 4: 145. doi:10.4172/2157-2518.1000145

Copyright: ( 2013 Halper J. This is an open-access article distributed under the terms of the Creative Commons Attribution License, which permits unrestricted use, distribution, and reproduction in any medium, provided the original author and source are credited. 